\title{
Papers
}

\section{Smoking, smoking cessation, and lung cancer in the UK since 1950: combination of national statistics with two case-control studies}

\author{
Richard Peto, Sarah Darby, Harz Deo, Paul Silcocks, Elise Whitley, Richard Doll
}

\begin{abstract}
Objective and design To relate UK national trends since 1950 in smoking, in smoking cessation, and in lung cancer to the contrasting results from two large case-control studies centred around 1950 and 1990. Setting United Kingdom.

Participants Hospital patients under 75 years of age with and without lung cancer in 1950 and 1990, plus, in 1990, a matched sample of the local population: 1465 case-control pairs in the 1950 study, and 982 cases plus 3185 controls in the 1990 study.

Main outcome measures Smoking prevalence and lung cancer.

Results For men in early middle age in the United Kingdom the prevalence of smoking halved between 1950 and 1990 but the death rate from lung cancer at ages 35-54 fell even more rapidly, indicating some reduction in the risk among continuing smokers. In contrast, women and older men who were still current smokers in 1990 were more likely than those in 1950 to have been persistent cigarette smokers throughout adult life and so had higher lung cancer rates than current smokers in 1950. The cumulative risk of death from lung cancer by age 75 (in the absence of other causes of death) rose from $6 \%$ at 1950 rates to $16 \%$ at 1990 rates in male cigarette smokers, and from $1 \%$ to $10 \%$ in female cigarette smokers. Among both men and women in 1990, however, the former smokers had only a fraction of the lung cancer rate of continuing smokers, and this fraction fell steeply with time since stopping. By 1990 cessation had almost halved the number of lung cancers that would have been expected if the former smokers had continued. For men who stopped at ages 60, 50, 40, and 30 the cumulative risks of lung cancer by age 75 were $10 \%$, $6 \%, 3 \%$, and $2 \%$.

Conclusions People who stop smoking, even well into middle age, avoid most of their subsequent risk of lung cancer, and stopping before middle age avoids more than $90 \%$ of the risk attributable to tobacco. Mortality in the near future and throughout the first half of the 21st century could be substantially reduced by current smokers giving up the habit. In contrast, the extent to which young people henceforth become persistent smokers will affect mortality rates chiefly in the middle or second half of the 21 st century.
\end{abstract}

\section{Introduction}

Medical evidence of the harm done by smoking has been accumulating for 200 years, at first in relation to cancers of the lip and mouth, and then in relation to vascular disease and lung cancer. ${ }^{1}$ The evidence was generally ignored until five case-control studies relating smoking, particularly of cigarettes, to the development of lung cancer were published in 1950, one in the United Kingdom ${ }^{2}$ and four in the United States. ${ }^{3-6}$ Cigarette smoking had become common in the United Kingdom, firstly among men and then among women, during the first half of the 20th century. By 1950 lung cancer rates among men in the United Kingdom had already been rising steeply for many years, but the relevance of smoking was largely unsuspected. ${ }^{27}$ At that time about $80 \%$ of men and $40 \%$ of women smoked (fig 1 and $B M J$ s website, table A). But few of the older smokers had smoked substantial numbers of cigarettes throughout their adult life, so even male lung cancer rates were still far from their maximum (except in younger men), and rates in women were much lower. Over the next few decades, a substantial decrease occurred in the United Kingdom in the prevalence of smoking (fig 1), in cigarette tar yields, and, eventually, in lung cancer rates (fig 2), and by 1990 male lung cancer mortality, although still high, was decreasing rapidly. ${ }^{8-12}$

In this paper we relate the UK national trends in smoking, in smoking cessation, and in lung cancer to the contrasting results from two large case-control studies of smoking and lung cancer in the United Kingdom that were conducted 40 years apart, centred on the years $1950^{27}$ and $1990 .^{8}$ The 1950 study was concerned with identifying the main causes of the rise in lung cancer and showed the predominant role of tobacco. The 1990 study was concerned not just with reconfirming the importance of tobacco but also with assessing the lesser effects of indoor air pollution of some houses by radon. ${ }^{8}$ Because there has been widespread cessation of smoking (indeed, above age 50 there are now twice as many former cigarette as current cigarette smokers in the United Kingdom ${ }^{10}$ ), the second study was able to assess the long term effects of giving up the habit at various ages.
Clinical Trial

Service Unit and Epidemiological Studies Unit (CTSU), Radcliffe

Infirmary, Oxford OX2 6HE

Richard Peto

professor of medical statistics and epidemiology

Sarah Darby professor of medical statistics

Richard Doll emeritus professor of medicine

Cancer

Epidemiology Unit, Radcliffe Infirmary, Oxford OX2 6HE

Harz Deo statistician

Trent Institute for Health Services Research, Queen's Medical Centre,

Nottingham NG7 2UH

Paul Silcocks senior lecturer in epidemiology

Department of Social Medicine, University of Bristol, Bristol BS8 2PR

Elise Whitley lecturer in medical statistics

Correspondence to: S Darby sarah.darby@ ctsu.ox.ac.uk

BMJ 2000;321:323-9

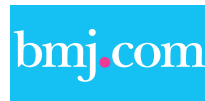

Further data are available on the $B M J$ 's website 


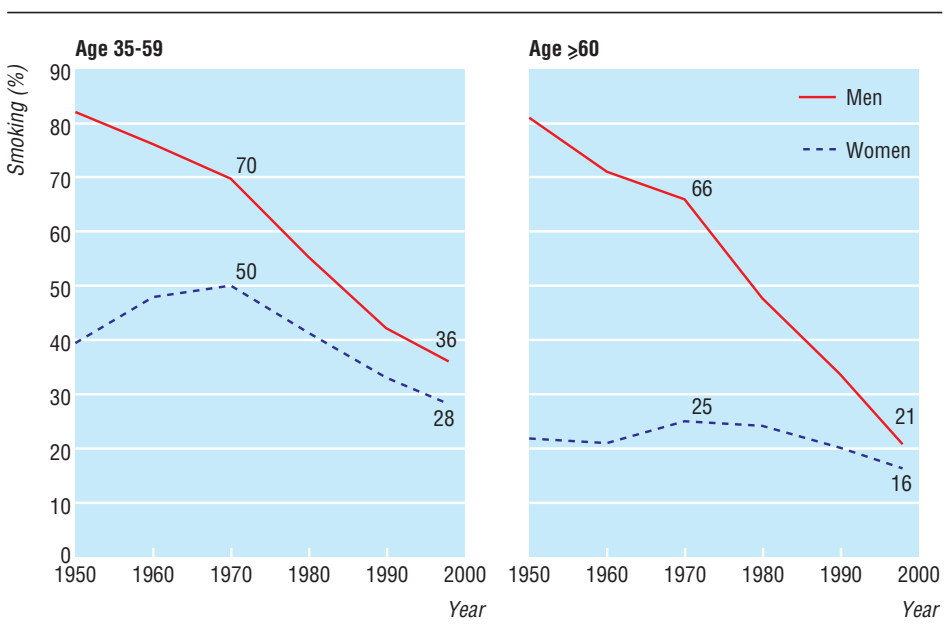

Fig 1 Trends in prevalence of smoking at ages 35-59 (left) and $\geqslant 60$ (right) in men and women in the United Kingdom, 1950-98. Prevalences at ages 25-34 were 80\% for men and $53 \%$ for women in $1948-52$ and $39 \%$ for men and 33\% for women in 1998 . Further details are given on the $B M S$ S website (table A)
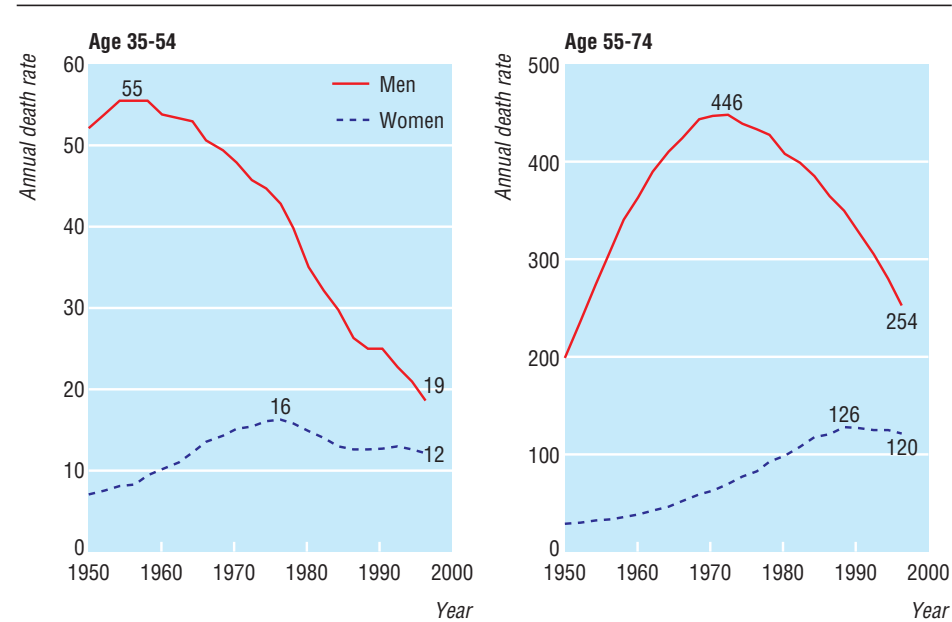

Fig 2 Trends in mortality from lung cancer in men and women in the United Kingdom, 1950-97: annual mortality per $10^{5}$ at ages 35-54 (left) and 55-74 (right) years. Rate in each 20 year age range is mean of rates in the four component five year age groups. Age specific rates from 1950-2 to 1993-7 are given on BMSS website (tables B and C); at ages 35-54 and 55-74 in 1998 the rates were 17 and 243 (men) and 12 and 20 (women)

\section{Participants and methods}

The 1950 study was conducted in London and four other large towns during 1948-52, and its methods have been described elsewhere. ${ }^{2}$ It involved interviewing, as potential "cases," patients younger than 75 years of age in hospital for suspected lung cancer and, as "controls," age matched patients in hospital with various other diseases (some of which would, in retrospect, have been conditions associated with smoking). After patients in whom the initial diagnosis of lung cancer was eventually refuted were excluded from the cases, 1465 cases and 1465 controls remained. A preliminary report on 709 case-control pairs was published in 1950, and the full results were published two years later. ${ }^{27}$

The 1990 study was conducted during 1988-93 in a part of southwest England that had not been included in the 1950 study. Potential cases were patients younger than 75 who were referred with suspected lung cancer to the five hospitals in Devon and Cornwall that investigated lung cancer. For each case a population control was obtained, selected randomly either from lists of the local family health services authority or from electoral rolls, and a hospital control was selected from patients whose current admission was for a disease not thought to be related to smoking. Controls were matched for age, sex, and broad area of residence to the patients with suspected lung cancer. Cases and controls were eligible for the 1990 study only if they were current residents of Devon or Cornwall, had lived in one of these two counties for at least 20 years, and could be interviewed in person by research assistants about smoking habits and other relevant characteristics. The final diagnosis of cases was sought; those who had a smoking related disease other than lung cancer were excluded; and the few who had a disease not known to be associated with smoking were transferred to the hospital control group. Similarly, in 1990 (although not in 1950) the final diagnosis of all the hospital controls was sought, and those whose main reason for being in hospital was a disease known to be related to smoking were excluded from the study.

The distributions of the smoking habits of the population controls and hospital controls in 1990 were closely similar, and the results are presented here with these two control groups combined. Further details of the study design and methods of data collection and analysis have been given elsewhere. ${ }^{8}$ Information was obtained in the 1990 study about the smoking habits of 667 men and 315 women with a confirmed diagnosis of lung cancer and of 2108 male and 1077 female controls.

\section{Statistical methods}

Relative and cumulative risks

Relative risks for men and women comparing particular categories of smoker with lifelong non-smokers in the 1990 study (and the ratios of the risks in former smokers to those in continuing smokers) were calculated by logistic regression with adjustment for age. $^{13}$ Further adjustment for social class, radon exposure, and county of residence made no material difference. Relative risks for men and women in the 1950 study were taken as the odds ratios indicated by the published frequency distributions of the age matched cases and controls. ${ }^{7}$ Relative risks from the studies were then combined with national lung cancer mortality rates from 1950 and 1990 respectively to estimate the absolute hazards in various categories of smoker, former smoker, and non-smoker. Because they are linked to known national rates, these absolute risks are statistically stable among smokers (and among former smokers), even though the risks relative to lifelong non-smokers would not be stable as so few non-smokers develop the disease. Such calculations of absolute risk allow comparisons between different categories of smoker not only within this study but also between this and other studies that report absolute risks.

For the 1990 study, within one particular age group, the absolute lung cancer rates for the different smoking categories were obtained by multiplying the all ages relative risks for each of the smoking categories 
Table 1 Comparisons of risk of lung cancer between all current smokers, all former smokers, and lifelong non-smokers in 1990 study

\begin{tabular}{|c|c|c|c|c|c|c|}
\hline \multirow[b]{2}{*}{ Smoking status } & \multicolumn{3}{|c|}{ Men } & \multicolumn{3}{|c|}{ Women } \\
\hline & $\begin{array}{l}\text { Cases/ } \\
\text { controls }\end{array}$ & $\begin{array}{l}\text { Ratio of } \\
\text { risks* }\end{array}$ & $\begin{array}{l}\text { No of cases expected } \\
\text { without cessationt }\end{array}$ & $\begin{array}{c}\text { Cases/ } \\
\text { controls }\end{array}$ & $\begin{array}{l}\text { Ratio of } \\
\text { risks* }\end{array}$ & $\begin{array}{l}\text { No of cases expected } \\
\text { without cessationt }\end{array}$ \\
\hline Current smoker & $379 / 602$ & 1.00 & 379 & $197 / 218$ & 1.00 & 197 \\
\hline \multicolumn{7}{|c|}{ Former smoker, by years stopped } \\
\hline$<10$ & $146 / 339$ & 0.66 & 222 & $68 / 93$ & 0.69 & 99 \\
\hline $10-19$ & $92 / 306$ & 0.44 & 208 & $18 / 80$ & 0.21 & 86 \\
\hline $20-29$ & $31 / 221$ & 0.20 & 152 & \multirow{2}{*}{$8 / 144 \ddagger$} & \multirow{2}{*}{$0.05 \ddagger$} & \multirow{2}{*}{$166 \ddagger$} \\
\hline$\geqslant 30$ & $16 / 240$ & 0.10 & 168 & & & \\
\hline Lifelong non-smoker & $3 / 400$ & $0.03 \S$ & 3 & $24 / 542$ & $0.05 \S$ & 24 \\
\hline Total & $667 / 2108$ & - & 1132 & $315 / 1077$ & - & 572 \\
\hline
\end{tabular}

*Risk ratio versus current smoker, adjusted for age.

†In former smokers, number of cases observed divided by risk ratio.

$\ddagger$ Women who stopped $\geqslant 20$ years ago.

$\S$ Lifelong risks for non-smokers taken from US prospective study.

by a common factor. This factor was chosen so that combination of these risks with the prevalences of such smoking habits among study controls in that age group yielded the 1990 age specific lung cancer death rate in that age group. If, for one particular category of smoker, the lung cancer rates per $10^{5}$ in all the five year age groups before age 75 add up to $c$, then the cumulative risk by age 75 is $1-\exp \left(-5 c / 10^{5}\right)$. For the 1950 study the relative risks were multiplied by 0.6 (men) and 0.5 (women) to yield the cumulative risk (\%) by age 75 . These factors were chosen to ensure that the population weighted means of the cumulative risks for lifelong non-smokers, former smokers, cigarette smokers, and other smokers were $4.7 \%$ (men) and $0.7 \%$ (women) as in the 1950 population. (The cumulative risk, which depends only on the age specific lung cancer rates up to age 75 and not on competing causes of death, is somewhat less than the lifetime risk.)

Use of statistically stable non-smoker rates from a large US study

The most reliable recent evidence on lung cancer rates among lifelong non-smokers in developed countries is that from a prospective study of mortality in one million Americans during the 1980s (see table D on $B M J$ s website). ${ }^{14}{ }^{15}$ These American rates seem to correspond not only to what normally happens in the United States but also to what normally occurs in the United Kingdom, at least among professional men. For, when these figures were used to predict the total number of deaths from lung cancer among the non-smokers in a cohort of male British doctors that has been followed prospectively for 40 years from 1951 to $1991,{ }^{16}{ }^{17}$ the number expected was 19.03 ; the number actually observed was 19 (R Doll, personal communication). The American lung cancer rates for non-smokers suggest cumulative risks by 75 years of age of $0.44 \%$ for men and $0.42 \%$ for women.

Cumulative risks for the different categories of smoker in the 1990 study are shown on the BM/s website (table E), representing the probabilities of death from lung cancer before age 75 : that calculated for lifelong non-smokers is $0.2 \%$ for men and $0.4 \%$ for women. The male rate is about half that in the American study but is based on only three cases, which is too few to be reliable. Conversely, the American results suggest that the cumulative risks calculated from the 1950 study $-0.6 \%$ (men) and $0.5 \%$ (women) in lifelong non-smokers-may be slightly too high, although the rate in men is based on only seven cases and was inflated by problems with the 1950 male controls (see Results). We have therefore used the American results for non-smokers in most of our analyses. This does not affect the risk ratios comparing smokers and former smokers or the estimated absolute risks among smokers and former smokers.

\section{Results}

\section{Effects of current smoking in 1990 study}

Most of the participants who were still current cigarette smokers in 1990 would have been cigarette smokers throughout adult life, and the cumulative risk of lung cancer by age 75 in this group was $15.9 \%$ for men and $9.5 \%$ for women (see $B M / \mathrm{s}$ website, table E). These cumulative risks reflect the death rates from lung cancer of cigarette smokers in 1990 and were obtained by combining the relative risks from the 1990 casecontrol study with national death rates. Had these men and women smoked as intensively when they were young as adolescent smokers do nowadays, the cumulative risks might have been greater. Only $34 \%$ of the male and $11 \%$ of the female controls who were current smokers had started before the age of 15 years, and the case-control comparisons indicate that smokers who had done so had double the risk of lung cancer of those who had started aged 20 or older (risk ratios adjusted for age and amount smoked were 2.3 (95\% confidence interval 1.4 to 3.8 ) for men and 1.8 (0.9 to 3.4) for women).

\section{Effects of cessation in 1990 study}

A large number of men and, to a lesser extent, of women had stopped smoking well before 1990. Hence, particularly for men, robust estimates can be obtained from the 1990 data of the effects of prolonged cessation on the avoidance of risk (table 1).

The ratio of the risk of lung cancer in those who have stopped smoking to that in continuing smokers gets progressively lower as the time since cessation gets longer, although it never gets quite as low as in lifelong non-smokers. Once people have started to smoke, however, the comparison that is relevant for them is of former smokers with continuing smokers, and table 1 contrasts the numbers of cases among former smokers with the numbers that would have been expected if smoking had continued. In the 1990 study there were 


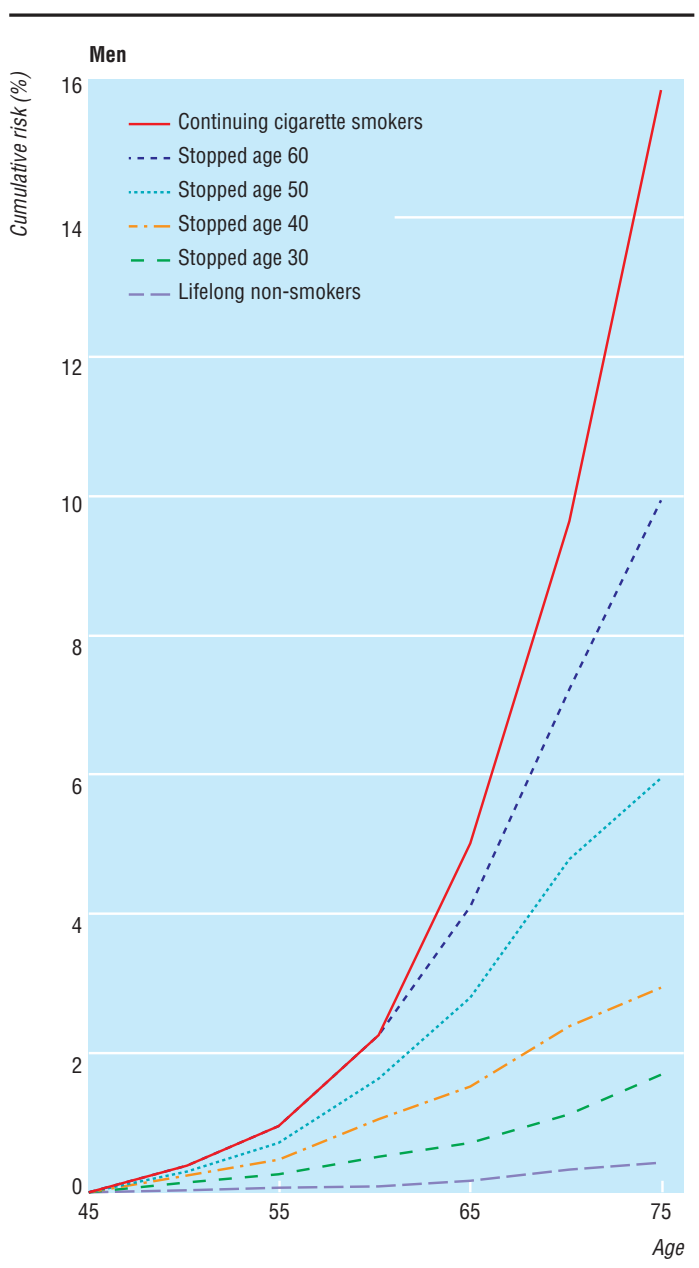

Fig 3 Effects of stopping smoking at various ages on the cumulative risk $(\%)$ of death from lung cancer up to age 75 , at death rates for men in United Kingdom in 1990. (Non-smoker risks are taken from a US prospective study of mortality ${ }^{14}$ )

substantially more former smokers than continuing smokers among the controls, and this widespread cessation had almost halved the number of cases that would have been expected if the former smokers had continued smoking. The risk ratios comparing former cigarette smokers with continuing cigarette smokers (see $B M J$ s website, table F) are essentially the same as those in table 1 for all smokers and can be used to calculate the cumulative risks of lung cancer for men who stop smoking cigarettes at different ages (fig 3). The cumulative risks by 75 years of age are $15.9 \%$ for men who continue to smoke cigarettes and 9.9\%, 6.0\%, $3.0 \%$, and $1.7 \%$ for those who stopped around 60,50 , 40 , and 30 years of age. The pattern among women was similar: the cumulative risk of lung cancer by age 75 among continuing smokers was $9.5 \%$ compared with $5.3 \%$ and $2.2 \%$ among women who stopped around 60 and 50 years of age, respectively. The risk seemed even smaller for women who had stopped earlier in life, but the number of such women was too small for statistical stability. The results for smokers and for former smokers in table 1 and figure 3 are not affected by any assumptions that may be made about non-smoker risks.
Comparison of findings for smoking in 1950 and 1990 studies

The hazards at the death rates among current smokers in the 1990 study, when the male lung cancer epidemic was well past its peak, can be compared with the hazards at the death rates among current smokers in the 1950 study $^{27}$ when the epidemic was still increasing rapidly, except among men in early middle age (table 2).

\section{Absolute risks in smokers unaffected by biases in 1950 male} controls

The findings in the earlier study were reported for categories of smoking that differ slightly from those now considered appropriate, but this probably makes little difference. In addition, the hospital controls in the earlier study included an unknown, but appreciable, proportion of patients who were in hospital for conditions that were subsequently shown to be related to smoking but were not known to be so in 1950 . This means that the proportion of smokers was higher than in the general population and also that the relative risks estimated from the 1950 study for different levels of smoking were too low. Both effects will have been relatively unimportant for women, as few women at that time had been smoking long enough to have been admitted to hospital because of a smoking related disease. Even for men, they will have had little effect on the calculated absolute risk among smokers. If, for example, the male rate of hospital admission for the control diseases was about 1.5 times as great among smokers as among non-smokers, then correction for this would multiply the relative risk of lung cancer in male smokers by about 1.5 and would indicate that the percentage of current smokers in the study areas was not $86 \%$, but about $80 \%$ (which was about the percentage in the country as a whole). But this correction would have no material effect on the cumulative risk calculated for cigarette smokers (and little effect on that calculated for other smokers or former smokers), as the weighted average has to remain $4.7 \%$ to match the 1950 male death rates. It would merely reduce the cumulative risk calculated for male non-smokers from $0.6 \%$ to about $0.4 \%$, thereby bringing it closer to that in US non-smokers.

\section{Changes in prevalence of smoking}

One clear difference between the 1950 and 1990 study results in table 2 is that many of the controls in the 1990 study had given up smoking, so there was a large decrease in the prevalence of smoking between the two studies. (In both 1950 (after correction) and 1990, the prevalence of smoking among controls resembled that in national surveys.) The reduction in the proportion currently smoking cigarettes was smaller in women than in men. Among women who still smoked in 1990, a higher proportion smoked heavily than was the case in 1950, and a substantially larger proportion had started before the age of $20(68 \%$ in 1990 and $24 \%$ in 1950 among women, compared with 83\% and $76 \%$ respectively among men). Moreover, the way that women smoke a cigarette has become more like the way men do. ${ }^{22}$ Nevertheless, among women old enough to be in the 1990 study more than half of those who had been cigarette smokers had given up the habit, and an even greater proportion of the men had 
Table 2 Smoking status versus cumulative risk of death from lung cancer by age 75, from 1950 and 1990 studies

\begin{tabular}{|c|c|c|c|c|c|c|c|c|}
\hline \multirow[b]{3}{*}{ Smoking status } & \multicolumn{4}{|c|}{ Men } & \multicolumn{4}{|c|}{ Women } \\
\hline & \multicolumn{2}{|c|}{$\%$ of cases/controls } & \multicolumn{2}{|c|}{ Cumulative risk (\%) } & \multicolumn{2}{|c|}{$\%$ of cases/controls } & \multicolumn{2}{|c|}{ Cumulative risk (\%) } \\
\hline & 1950 & 1990 & $1950^{*}$ & 1990 & 1950 & 1990 & $1950^{*}$ & 1990 \\
\hline Lifelong non-smoker & $0.5 / 4.5$ & $0.5 / 19.0$ & $\sim 0.4$ & $\sim 0.4$ & $37.0 / 54.6$ & $7.6 / 50.3$ & $\sim 0.4$ & $\sim 0.4$ \\
\hline Former smokers & $5.2 / 9.1$ & $42.7 / 52.5$ & 2.9 & 5.5 & $9.3 / 7.4$ & $29.8 / 29.4$ & 0.9 & 2.6 \\
\hline Current pipe or cigar only & $3.9 / 7.2$ & $8.5+/ 7.1$ & 2.8 & $8.1 \dagger$ & $0 / 0$ & $0.6 / 0.1$ & - & - \\
\hline Current cigarette smokers & $90.4 / 79.2$ & $48.3 / 21.5$ & 5.9 & 15.9 & $53.7 / 38.0$ & $61.9 / 20.1$ & 1.0 & 9.5 \\
\hline \multicolumn{9}{|c|}{ Amount smoked (\% of smokers) $\ddagger$} \\
\hline$<5 /$ day & $3.6 / 7.0$ & $6.2 \S / 9.5$ & 2.8 & $10.4 \S$ & $20.6 / 36.7$ & $4.1 \S / 10.1$ & 0.6 & $3.4 \S$ \\
\hline 5-14/day & $38.2 / 47.5$ & $33.5 / 39.7$ & 4.4 & 12.8 & $44.1 / 44.9$ & $32.3 / 37.8$ & 1.0 & 7.7 \\
\hline 15-24/day & $33.0 / 31.5$ & $39.1 / 37.3$ & 5.7 & 16.7 & \multirow{2}{*}{$35.3 / 18.4^{\star \star}$} & $44.1 / 42.4$ & \multirow{2}{*}{$2.0^{* \star}$} & 10.4 \\
\hline$\geqslant 25 /$ day & $25.2 / 14.0$ & $21.1 / 13.5$ & 9.8 & 24.4 & & $19.5 / 9.7$ & & 18.5 \\
\hline Total & $100 / 100$ & $100 / 100$ & & & $100 / 100$ & $100 / 100$ & & \\
\hline No of cases & $1357 / 1357$ & $667 / 2108$ & - & - & $108 / 108$ & $315 / 1077$ & - & - \\
\hline
\end{tabular}

*The cumulative risk by age 75 in 1950 was estimated for smokers and former smokers by multiplying the published relative risks ${ }^{7}$ by 0.6 for men and 0.5 for women. This, together with the population prevalences, yields the cumulative risks of $4.7 \%$ for men and $0.7 \%$ for women seen in 1950 UK national statistics (see BMJ's website). That for lifelong smokers in 1950 and 1990 was estimated from a US prospective study.

†The effects of smoking only pipes or cigars cannot be assessed here, as $88 \%$ of these cases had previously smoked cigarettes.

†By tobacco most recently smoked (1950 study, taking $1 \mathrm{~g}$ of other tobacco as one cigarette) or by current cigarettes (1990 study).

§The effects of $<5$ cigarettes a day cannot be assessed here, as $93 \%$ of these cases had previously smoked over 15 a day and several had smoked over 30 .

**Women in 1950 study who smoked $\geqslant 15$ cigarettes a day.

done so. A recent national survey confirms that among men and women aged over 50 in the United Kingdom, the number of former cigarette smokers is double the number of continuing cigarette smokers. ${ }^{10}$ But those who are continuing smokers nowadays may well have smoked substantial numbers of cigarettes throughout adult life, whereas national cigarette sales during the first few decades of the last century ${ }^{918}$ show that few of the older smokers in 1950 can have done so.

Changes in lung cancer rates among continuing smokers Another clear difference between the two studies is that the cumulative risk of lung cancer among smokers increased substantially. The increase occurred not only among women (among whom the cumulative risk for cigarette smokers was $1.0 \%$ in 1950 and $9.5 \%$ in 1990) but also among men (among whom it increased from $5.9 \%$ at 1950 cigarette smoker lung cancer rates to $15.9 \%$ at 1990 rates). As lung cancer mainly occurs above the age of 55, the increase in the cumulative risk is mainly because current smokers aged 55-74 in 1950 were less likely to have smoked a substantial number of cigarettes throughout adult life than current smokers in $1990 .{ }^{18}{ }^{19}$ Among younger men, however, the death rate from lung cancer decreased more rapidly than the prevalence of smoking (figs 1 and 2 ), indicating lower death rates from lung cancer in 1990 than 1950 among male cigarette smokers in early middle age.

\section{Discussion}

\section{Prolonged cigarette smoking}

The 1990 study provides reliable evidence, particularly among men, about the absolute effects of prolonged cigarette smoking and about the effects of prolonged cessation (table 1, fig 3). Information about the effects of prolonged cigarette smoking could not have been obtained in 1950 because the habit became widespread in the United Kingdom (firstly among men and then among women) only during the first half of the 20th century. By 1950 the increase in smoking was too recent to have had its full effects on disease rates, except perhaps among men in early middle age. The fact that by 1990 many of the current smokers would have smoked substantial numbers of cigarettes throughout adult life is the chief reason for the large increase in the cumulative risk of lung cancer among continuing smokers. ${ }^{19}$ For the same reason, increases in the risks associated with smoking were also seen between the first 20 years (1951-71) and the next 20 years (1971-91) of follow up in the prospective study of smoking and death among British doctors, ${ }^{17}$ and between the two large prospective studies carried out by the American Cancer Society in the 1960s and 1980s. ${ }^{15} 20$

At the lung cancer rates for female cigarette smokers in 1950 the cumulative risk of death from lung cancer before age 75 (in the absence of other causes of death) would have been only $1 \%$ compared with $10 \%$ at 1990 rates. The effect of longer exposure (together with the effect of changes in the way women smoke cigarettes $^{22}$ ) overwhelms the lesser effect of the reduction in cigarette tar yields (and of other changes in cigarette composition) over this period. ${ }^{19}$

Among male cigarette smokers the cumulative risk of death from lung cancer by age 75 increased from $6 \%$ in 1950 to about $16 \%$ in 1990. Again the most plausible explanation for this increase is that the effect among continuing smokers aged 55-74 of a greater duration of smoking substantial numbers of cigarettes outweighed the effect of changes in cigarette composition. At ages 35-54, there was a twofold decrease between 1950 and 1990 in the prevalence of smoking among men, but, particularly at ages 35-44, male mortality from lung cancer in the United Kingdom decreased more rapidly than the prevalence of smoking (figs 1 and 2), suggesting a decrease in hazard among smokers. These increases and decreases in the hazards among smokers, together with large changes in smoking uptake rates and cessation rates, underlie the large fluctuations in UK lung cancer death rates shown in fig 2 and reviewed in more detail elsewhere. ${ }^{19} 2123$

\section{Prolonged cessation}

In the 1990 study we were able to assess the effects of prolonged cessation among those who had smoked cigarettes for many years. Although efforts to change 
from cigarettes to other types of tobacco, or from smoking substantial numbers of cigarettes to smoking smaller numbers, seemed to confer only limited benefit (table 2), stopping smoking confers substantial benefit. Figure 3 indicated that even people who stop smoking at 50 or 60 years of age avoid most of their subsequent risk of developing lung cancer, and that those who stop at 30 years of age avoid more than $90 \%$ of the risk attributable to tobacco of those who continue to smoke (see fig 3 and $B M$ Js website, table G). In the United Kingdom widespread cessation has roughly halved the number of cases of lung cancer that would now be occurring, as by 1990 it had already almost halved the number that would have occurred in the study (table 1).

\section{Past and future trends in total mortality} attributable to tobacco

Despite cessation of smoking and improvements in cigarette composition, lung cancer is still the chief neoplastic cause of death in the United Kingdom, and tobacco causes even more deaths from other diseases than from lung cancer. ${ }^{14}{ }^{15}$ The changes since 1950 in tobacco-attributable mortality from diseases other than lung cancer can be estimated indirectly from national mortality statistics. ${ }^{15}$ Such estimates indicate that in 1965 the United Kingdom probably had the highest death rate from tobacco related diseases in the world, but that since then the number of deaths in middle age (35-69) from tobacco has decreased by about half, from 80000 in 1965 to 43000 in 1995 . Nevertheless, cigarette smoking remains the largest single cause of premature death in the United Kingdom and eventually kills about half of those who persist in the habit. ${ }^{17}$ The 1990 study assessed the effects of stopping smoking only on lung cancer, but a comparably large benefit of stopping was found for all cause mortality in the prospective study of smoking and death among British doctors. ${ }^{17}$ This reinforces similar evidence from many other countries that even in middle age those who stop smoking avoid most of their subsequent risk of being killed by tobacco.

Two thirds of those in the United Kingdom who are still current smokers say they want to give up the habit, ${ }^{10}$ and the extent to which they succeed in doing so will be the chief determinant of the number of deaths caused by tobacco over the next few decades. Both in the United Kingdom and elsewhere, ${ }^{24}{ }^{25}$ the extent to which young people become cigarette smokers over the next few decades will strongly affect mortality only in the middle and second half of the 21st century, but mortality in the first half of the century will be affected much less by the numbers of new smokers who start than by the numbers of current smokers who stop.

We thank the individuals and research assistants who took part in both studies; the staff in hospitals, general practices, and the South and West Cancer Intelligence Unit; Cathy Harwood and Anthea Craven for secretarial assistance; and Jillian Boreham for graphics.

Contributors: RD planned the 1950 study with A BradfordHill and planned the 1990 study with SD. SD, RD, HD, PS, and EW conducted and analysed the 1990 study in the Imperial Cancer Research Fund Cancer Epidemiology Unit. RP, SD, and $\mathrm{RD}$ planned and wrote the paper. SD is the guarantor.

Funding: direct support to Clinical Trial Service Unit from the Medical Research Council (which also funded the 1950 study), the British Heart Foundation, and the Imperial Cancer Research Fund. The 1990 study was funded by the Imperial

\section{What is already known on this topic}

Smoking is a cause of most deaths from lung cancer in the United Kingdom

Early studies could not reliably assess the effects of prolonged cigarette smoking or of prolonged cessation

\section{What this study adds}

If people who have been smoking for many years stop, even well into middle age, they avoid most of their subsequent risk of lung cancer

Stopping smoking before middle age avoids more than $90 \%$ of the risk attributable to tobacco

Widespread cessation of smoking in the United Kingdom has already approximately halved the lung cancer mortality that would have been expected if former smokers had continued to smoke

As most current smokers in the United Kingdom have consumed substantial numbers of cigarettes throughout adult life, their risks of death from lung cancer are greater than earlier studies had suggested

Mortality from tobacco in the first half of the 21st century will be affected much more by the number of adult smokers who stop than by the number of adolescents who start

Cancer Research Fund; the National Radiological Protection Board; the Department of Health; the Department of the Environment, Transport and the Regions; and the European Commission.

Competing interests: None declared.

1 Doll R. Uncovering the effects of smoking: historical perspective. Stat Methods Med Res 1998;7:87-117.

2 Doll R, Hill AB. Smoking and carcinoma of the lung. Preliminary report. BMJ 1950;ii:739-48.

3 Wynder EL, Graham EA. Tobacco smoking as a possible etiologic factor in bronchogenic carcinoma. JAMA 1950;143:329-36.

4 Levin ML, Goldstein H, Gerhardt PR. Cancer and tobacco smoking. JAMA 1950;143:336-8.

5 Mills CA, Porter MM. Tobacco smoking habits and cancer of the mouth and respiratory system. Cancer Res 1950;10:539-42.

6 Schrek R, Baker LA, Ballard GP, Dolgoff S. Tobacco smoking as an etiologic factor in disease. Cancer Res 1950;10:49-58.

7 Doll R, Hill AB. A study of the aetiology of carcinoma of the lung. BMJ 1952;ii:1271-86.

8 Darby S, Whitley E, Silcocks P, Thakrar B, Green M, Lomas P, et al. Risk of lung cancer associated with residential radon exposure in southwest England: a case-control study. BrJ Cancer 1998;78:394-408.

9 Nicolaides-Bouman A, Wald N, Forey B, Lee PN. International smoking statistics. Oxford: Oxford University Press, 1993.

10 Office for National Statistics. Results from the 1998 general household survey. London: Stationery Office, 2000.

11 Office for National Statistics. Mortality statistics, general: 1993, 1994 and 1995. London: Stationery Office, 1997.

12 World Health Organization. Mortality statistics for the United Kingdom, 1950-1997. http://www.who.int/whosis/mort.

13 Stata Corporation. Stata Statistical Software: Release 5.0. College Station, TX: Stata Corporation, 1997.

14 Peto R, Lopez A, Boreham J, Thun M, Heath C. Mortality from tobacco in developed countries: indirect estimation from national vital statistics. Lancet 1992:339:1268-78.

15 Peto R, Lopez A, Boreham J, Thun M, Heath C. Mortality from tobacco in developed countries: indirect estimation from national vital statistics. Oxford: Oxford University Press, 1994.

16 Doll R, Peto R. Mortality in relation to smoking: 20 years' observations on male British doctors. BMJ 1976;ii:1525-36.

17 Doll R, Peto R, Wheatley K, Gray R, Sutherland I. Mortality in relation to smoking: 40 years' observations on male British doctors. BMJ 1994:309:901-11. 
18 Wald N, Kiryluk S, Darby S, Doll R, Pike M, Peto R. UK smoking statistics. Oxford: Oxford University Press, 1988.

19 Doll R, Peto R. The causes of cancer: quantitative estimates of avoidable risks of cancer in the United States today. J Natl Cancer Inst 1981;66:1191308

20 Thun MJ, Day-Lalley CA, Calle EE, Flanders WD, Heath CA. Excess mortality among cigarette smokers: changes in a 20-year interval. Am J Pub Health 1995:85:1293-30.

21 Peto R. Overview of cancer time-trend studies in relation to changes in cigarette manufacture. In: Zaridze D, Peto R, eds. Tobacco: a major international health hazard. Lyons: International Agency for Research on Cancer, 1986:211-26. (IARC scientific publication No 74.)
22 Doll R, Gray R, Hafner B, Peto R. Mortality in relation to smoking: 22 years' observation on female British doctors. BMJ 1980;280:967-71

23 Doll R, Darby S, Whitley E. Trends in mortality from smoking-related diseases. In: Charlton J, Murphy M, eds. The health of adult Britain, 1841-1994. Vol 1. London: Stationery Office, 1997:128-55.

24 Peto R, Chen ZM, Boreham J. Tobacco-the growing epidemic. Nature Med 1999;5:15-7.

25 Peto R, Lopez AD. The future worldwide health effects of current smoking patterns. In: Koop CE, Pearson CE, eds. Global health in the 21st century. New York: Jossey-Bass, 2000.

(Accepted 7July 2000)

\section{Smoking reduction with oral nicotine inhalers: double blind, randomised clinical trial of efficacy and safety}

Chris T Bolliger, Jean-Pierre Zellweger, Tobias Danielsson, Xandra van Biljon, Annik Robidou, Åke Westin, André P Perruchoud, Urbain Säwe

\begin{abstract}
Objectives To determine whether use of an oral nicotine inhaler can result in long term reduction in smoking and whether concomitant use of nicotine replacement and smoking is safe.

Design Double blind, randomised, placebo controlled trial. Four month trial with a two year follow up. Setting Two university hospital pulmonary clinics in Switzerland.

Participants 400 healthy volunteers, recruited through newspaper advertisements, willing to reduce their smoking but unable or unwilling to stop smoking immediately.

Intervention Active or placebo inhaler as needed for up to 18 months, with participants encouraged to limit their smoking as much as possible.

Main outcome measures Number of cigarettes smoked per day from week six to end point. Decrease verified by a measurement of exhaled carbon monoxide at each time point compared with measurement at baseline.

Results At four months sustained reduction of smoking was achieved in $52(26 \%)$ participants in the active group and $18(9 \%)$ in the placebo group $(\mathrm{P}<0.001$; Fisher's test). Corresponding figures after two years were $19(9.5 \%)$ and $6(3.0 \%)(\mathrm{P}=0.012)$.

Conclusion Nicotine inhalers effectively and safely achieved sustained reduction in smoking over 24 months. Reduction with or without nicotine substitution may be a feasible first step towards smoking cessation in people not able or not willing to stop abruptly.
\end{abstract}

\section{Introduction}

The best way to prevent the detrimental health consequences of cigarette smoking is to quit, and efforts to date have focused on this strategy. ${ }^{2}$ Many smokers, however, find it impossible to quit, even with help, because of their dependence on nicotine, which is a highly addictive psychoactive drug. ${ }^{3}$ Nicotine replacement therapy is an established pharmacological aid to help smokers quit and has consistently been shown almost to double the abstinence rate, irrespective of the level of additional interventions. ${ }^{4}$ Increasing experience with trials on smoking cessation, however, has shown that successful abstinence is usually obtained in smokers with low to moderate nicotine dependence, whereas heavily dependent smokers have the highest relapse rates. ${ }^{5}$ Unfortunately this latter group has the highest cigarette consumption and is therefore at the highest risk of developing disease related to tobacco consumption.

Given that few smokers are ready to quit at any time, plus the fact that many smokers try to quit several times before succeeding, new treatment approaches are clearly needed. One such strategy could be to reduce tobacco consumption substantially in smokers who are unwilling or unable to quit right away. For such smokers, sustained reduction might reduce the known health risks by reducing tobacco exposure and may also move them towards the ultimate goal of quitting. ${ }^{6}$ In a preliminary study Fagerström et al showed that short term smoking reduction with nicotine replacement therapy over a period of five weeks was possible and that the combination of reduced smoking with nicotine replacement therapy was well tolerated. The efficacy and safety of nicotine replacement therapy in achieving sustained smoking reduction, however, has not yet been assessed. Another important issue is whether smoking reduction can increase motivation to quit in recalcitrant smokers.

Smoking cessation is no longer regarded as a dichotomous process (cessation or not) but rather as a continuum that entails several stages, as described by DiClemente and Prochaska. $^{9}$ There is empirical evidence to suggest that reduced smoking, also referred to as controlled smoking or harm reduction, is a therapeutic option for those smokers unable or unwilling to quit. Glasgow et $\mathrm{al}^{10}$ and Hughes et $\mathrm{al}^{11}$ found that smokers randomised to such an intervention were no less likely, and possibly even more likely, to quit smoking in the long term compared with smokers randomised to more conventional interventions. While not the first treatment of choice, reduced smoking might be considered for recalcitrant smokers unwilling to repeat traditional cessation attempts.
Respiratory

Division,

Department of

Internal Medicine,

University Hospital

4031 Basle,

Switzerland

Chris T Bolliger associate professor

Xandra van Biljon

registered nurse

André P

Perruchoud

professor

University Medical

Policlinic, CHUV,

1000 Lausanne,

Switzerland

Jean-Pierre

Zellweger

lecturer

Annik Robidou

registered nurse

Pharmacia and

Upjohn, 25109

Helsingborg,

Sweden

Tobias Danielsson

clinical research

manager

Åke Westin

head of biostatistics

Urbain Säwe

medical adviser

Correspondence to: C T Bolliger

ctb@gerga.sun.ac.za

BMJ 2000;321:329-33

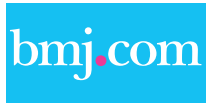

This article is part of the BMJ's randomised controlled trial of open peer review. Documentation relating to the editorial decision making process is available on the BMJ's website 